\title{
Influence of Teacher Behaviors on Student Activities in Information-Based Classroom Teaching
}

\author{
https://doi.org/10.3991/ijet.v17i02.28271 \\ Linsheng Wang \\ College of Electronic Information Engineering, Henan Polytechnic Institute, Nanyang, \\ China \\ wanglinsheng@hnpi.edu.cn
}

\begin{abstract}
Under the background of teaching requirements comprehensively satisfied by information hardware, clarifying the influencing factors of teaching behaviors on student activities in the information-based teaching, as well as the influence mechanism. In this paper, a mediator model was established. Next, the collaboration degree in the teaching process was taken as the influencing factor and information monitoring was used as the mediating variable to discuss the effect of teaching behaviors on student activities in the classroom teaching process. Subsequently, the structural equation model (SEM) was used to mine the relationship between teaching behaviors and student activities and the influence on student activities. It was discovered that the overall Cronbach's a value of questionnaires was 0.920 , indicating a favorable questionnaire reliability; the KMO value was 0.916 , which represents excellent questionnaire validity; three factors - teachers' teaching behaviors, collaboration degree, and media monitoring - have shown positively strong correlations with student activities. The research results have provided realistic examination for enriching information-based classroom factors like teaching concepts, teaching resources and teaching quality, mine the existing problems and further provide reform orientation for promoting the high-efficiency development of information-based teaching, completing the effective engagement between information technology and specialized courses, and integrating abundant information-based teaching resources.
\end{abstract}

Keywords-informatization, teacher behaviors, student activities, structural equation model (SEM)

\section{Introduction}

In the global era of a comprehensive information-based society, information and knowledge have become one of the productivity factors. This productivity-driven social reform permeates into various fields of the economy, society, culture, and life, and it will infiltrate through each capillary of society, finally gaining access to each nerve terminal. The education sector, which is the place of origin for cultivating people into knowledge carriers, undertakes the responsibility for spreading and populariz- 
ing knowledge. The educational informatization is an essential route for future educational reform and development. If the educational informatization reform is not completed, this will certainly result in the unmatching and maladaptation between educational development and social development, stall the talent cultivation progress and further affect the progress of productivity. Since the 21 st century, all kinds of technologies such as artificial intelligence (AI), virtual reality (VR) and cloud computing have achieved fruitful results in improving the social production efficiency and promoting social development. With the advancement of information-based teaching level in colleges and universities, education administrators started seeking for new teaching breakthroughs from richer perspectives. As an international cutting-edge technology, information-based teaching has displayed powerful functions in the aspects of precision teaching, learning situation analysis and teaching evaluation. The information-based classroom generally refers to the classroom teaching activity conducted by information-based means. The typical forms of information-based classrooms include flipped classrooms, open education, and MOOC. The application of information-based classrooms has enhanced the classroom teaching efficiency without any doubt, but for the application of new technologies, some doubts and plights still remain to be solved in the field of education.

From the Ten-Year Development Plan of Educational Informatization to Action Plan of Educational Informatization 2.0 formulated in China, the national advocation and guidance for the implementation of information-based education have been continuously strengthened. The current informatization construction in colleges and universities have always been conducted by centering on information technologies. However, given the diversity and suitability difference of information technologies, optimizing the information-based classroom teaching strategy by way of reform is the key to guide the innovation of teaching concepts, cultivate classroom learning interests, and realize the high-efficiency application of information technologies. With the continuously deepened integration of information technologies, which exert revolutionary effects on the educational development into the classroom teaching, they have evolved from an exogenous variable affecting the educational development into an endogenous variable for reforming the educational system structure. The information technologies have promoted the comprehensive cultivation of individualized innovative talents, who meet the needs of the times, while reconstructing the teaching environment, thus reorganizing the teaching contents and reforming the teaching approach and learning evaluation. The teaching reform driven by information technologies is not spontaneously generated due to the application of information technologies. Instead, it is gradually formed through the changes in teaching and learning activities and teaching approaches during the teaching and learning process.

Information-based teaching is an auxiliary teaching approach adapting to the current "Internet + " concept. Based on information technologies, information-based teaching highlights the student-oriented educational principle and realizes the innovative high-quality development of professional teaching by optimizing the thinking mode and approach of teaching. From internal structural influencing factors, the information-based teaching reform comprises teaching concept, teaching process design, teaching content positioning, teaching evaluation strengthening, teaching envi- 
ronment creation, and so on. According to the related definition of national educational informatization and combining the realistic demand and research orientation of information-based teaching, it is under the application and assistance of information technologies. In colleges and universities, information technology can run through the teaching process of all specialties, which can be divided into three phases: teaching preparation, teaching implementation, and educational evaluation. No strict criterion exists that judge whether a teacher implements the information-based teaching. Regardless of the phases, a teacher will be considered conducting information-based teaching only if he/she applies any information technology to classroom teaching behaviors, and such classroom is an information-based classroom. Although the information-based classroom has become the mainstream development trend, teaching is a nonlinear complex system and a teacher-student interaction process. Therefore, student activities are affected intimately by teacher behaviors in the informationbased classroom without any doubt.

\section{Theoretical background and research hypotheses}

\subsection{Theoretical background}

In the information-based classroom, teachers should take full advantage of internet information technologies, integrate massive learning resources, provide the aforementioned resources uniformly on online learning platforms, and conduct the optimization design of courses to facilitate students to selectively learn. They should sort the learning resources by classification and conduct hierarchical teaching and guidance work from basic knowledge to knowledge application and knowledge extension capability. Students can select the learning resources within the scope of their learning objectives from network platforms, and the resources should support individualized learning, breakthrough learning, or mission-type learning, making it possible for students to experience the sense of achievement from the objective realization during the learning process to motivate their enthusiasm for deep discussion, research, and learning. As the guides of student knowledge resources, teachers should assist students in formulating their learning strategies, plans and objectives. Teachers should make pertinent learning diagnosis for students by means of internet information technology and provide timely feedback to students. Moreover, teachers can set the corresponding learning diagnostic analysis questionnaire, assignment or test, design different question types in different learning phases, and facilitate students to understand their own present mastery degree of learned knowledge through learning diagnostic analysis. If the learning diagnostic analysis shows that the students fail to pass the elementary stage of knowledge application and reveals which knowledge points remain to be strengthened, then the students can realize pertinent self-consolidation and learning, make self-reflections through the diagnostic information, make correct judgments and further improve their self-learning abilities. Under the background of information technology, teachers, as the facilitators of student learning, should create learning spaces and environments, drive students to do autonomous, cooperative and inquiry 
learning, and cultivate their critical thinking and innovative spirit. Information technology platforms should provide the exchange and discussion zones; thus each student can speak out freely on the platforms, dare to propose their own ideas over academic problems and gradually verify them, or join in the learning teams on the platforms to improve their own teamwork competency.

The existing studies have been mainly implemented through literature research, scales, questionnaires, empirical studies, and so on. According to related findings, the teaching environment, resources, activities, learners, and teachers mainly influence student learning in information-based teaching. The index system adopted may vary from country to country and from author to author; however, the student learning factors have been analyzed as a whole from a macro level in most of the existing studies, and the investigation method has been mainly utilized. However, the factors influencing student learning have been scarcely analyzed through specific teacher behaviors by starting from the concrete classroom teaching behaviors. Given that the teachers' teaching behaviors are the key to improving the classroom teaching quality and the gravity point of teaching reform, with important effects on the development of student learning, teacher behaviors have become the external basis for student development and can trigger, maintain, and promote students' learning behaviors. Hence, based on the subject-object (teacher behaviors and student activities) interaction in the information-based classroom teaching, the monitoring $\&$ management of informationbased classroom was incorporated as a mediating variable in this paper to analyze the influences of the teachers' teaching behaviors on students' classroom activities. Aside from breaking through the traditional "across the board, quick march" standard teaching and "teacher, teaching material, and classroom"-centered lecture-style classroom, the research results are also expected to realize the reform of educational and teaching model and reconstruction of school management system under the support of information technology and contribute to the important effects of information technology on educational development.

\subsection{Research hypotheses}

Under the information-based classroom environment, the teachers' teaching behaviors can be divided into self-teaching behaviors, collaborative teaching behaviors and media supervisory behaviors. As for the main teaching behaviors, teachers provide lectures and presentations in classrooms based on teaching contents, which are planned and arranged by teachers to affect the overall teaching quality. Collaborative teaching behaviors refer to classroom behaviors, such as questioning and feedback. Media supervisory behaviors aim to promote the smooth implementation of main teaching behaviors, including the utilization of information resources and feedback of information-based supervision. The influences of teacher behaviors on student activities in information-based classroom teaching have been widely explored. With the fusion and application of information technologies in classroom teaching, the unilateral teaching behaviors of teachers in classroom teaching will hinder the students' autonomous learning and cooperative learning, where the former exerts promoting effects on the latter and the teachers' supporting behaviors. 
From the teachers' teaching behaviors under the information environment, Teo T et al. [1] evaluated the self-reported willingness of Singaporean and Malaysian preservice teachers to use the information technologies in the future; Stes et al. [2] investigated the influence of teaching development on students perceived teacher behaviors, and the repeated analyses of variance and covariance showed that the teaching behaviors were insignificantly affected by the teaching development; Wang J et al. [3] analyzed the differences of high school physics teachers in Beijing, Taipei, and Chicago on their understanding levels of inquiry teaching under the cloud learning environment. Results revealed that the teachers from Beijing paid attention to teachers when understanding the inquiry teaching, while those from Chicago centered on students; Babad E et al. [4] measured the different influences of teacher behaviors and nonverbal and verbal instantaneity on teaching effect, as the information technologies continuously entered the teaching process, the teaching environment gradually became open with ever-diversified functions. The information-based classroom teaching under the technical support should fully manifest the "student-centered" teaching concept, and teachers are transformed from knowledge transmitters into teaching guides and auxiliaries who should design teaching adaptable to student learning and improve the educational and teaching quality by taking the objectives of cultivating students' lifelong learning ability, as well as cognitive ability, cooperative ability and innovation ability adapting to the development of the times. Teaching behaviors are an important part of classroom, which affects and decides the implementation of teaching process to some extent, along with significant effects on students' classroom activities and behaviors. However, under the background of information-based classroom teaching, excessive teaching behaviors exist, and teachers are excessively taken as the center of teaching, which can easily lead to students' positional deviation, reduced frequency of student activities, and their weakened enthusiasm.

Teacher behaviors are negatively correlated with student activities in information-based classroom. Under the information environment, student-teacher interaction becomes sufficient. For instance, Fisher D et al. [5] indicated that student perception of their learning environment was mapped through the interaction with teachers, and the teacher-student interaction presented an intense association with learning effect; Rankin et al. [6] deemed that the interaction links in classroom teaching could be increased and revealed that this could effectively support the positive evaluation of students' learning abilities; Kindeberg $\mathrm{T}$ [7] stated that teachers exert crucial effects on student willingness to interact and share knowledge, skills and values with teachers, thus it was necessary to improve the teachers' cognition of interactive teaching approach; Silverman R. D. et al. [8]discussed about the relationship between teacher guidance teaching grade 3-5 students and student vocabulary and understanding level, and revealed that teachers' language state interacted with the teachers' teaching effect, and the teaching concerning compression strategy was associated with the greater positive changes in the understanding ability of bilingual students; Minamishima et al. [9] stated that teachers' teaching behaviors were important factors affecting the teaching quality and students enjoyed higher scores in the class, including more participatory behaviors. Schipper T et al. [10] discussed about whether the participatory classroom learning would influence the self-efficacy belief and teaching behaviors of 
teachers, and determined that positive and effective interaction could obviously enhance the students' enthusiasm for classroom learning; Menninga A. et al. [11] discussed about the Q \& A-like interaction of teachers and young students in science class, and the results manifested that richer chapters and more interactions appeared in classrooms through the interactive teaching approach, and the teaching effect could be obviously improved through teachers' open-ended questions and students' reasoning. The information of information technology in education and teaching still rests on the simple application of instruments, and the educational and teaching model reform and school management system reconstruction under the support of information technology can even hardly generate any revolutionary effect on the educational development; lecturing still plays a dominant role in the teaching process during the classroom transformation. Therefore, classroom teaching under the information environment can improve the effect of student activities only through the sufficient teacher-student interaction.

Collaboration degree is positively correlated with student activities in information-based classroom. The informatization itself can enhance the student activity degree in classrooms. For instance, Liu et al. [12] proposed an individualized elearning system based on item response theory, and the results showed that the learning efficiency could be improved by information-aided teaching; Hanson et al. [13] investigated the effect achieved by the informatization in teaching, and revealed that favorable teaching practices were positively correlated with the undergraduate expectation for postgraduate education; by taking 208 students in Fujian University of Technology as the study objects, Li [14] conducted a 15-week (three hours per week, 45 hours in total) experimental teaching, and used the analysis of variance (ANOVA) to discuss the influence of synchronous network teaching on the creativity of art school students, and the results manifested that network-based synchronous teaching enabled the mutual sharing of audio, picture, and even film, so as to enrich the learning media. With the fusion and application of information technology in classroom teaching, the unilateral teaching behaviors of teachers in classroom teaching will impede the students' autonomous learning and cooperative learning, where the former exerts promoting effects on the latter and the teachers' supporting behaviors. In the flipped classroom teaching, the learning-related concrete learning tasks, learning materials, learning evaluation, teaching activity design and classroom teaching will influence student learning. Hence, it is an essential trend to perform the statistical analysis and draw the portrait of student users through media monitoring of student activities and acquiring all information of student activities by means of information technology in the information environment.

Media monitoring has a significant positive correlation with student activities in information-based classroom. Based on the aforementioned research hypotheses, a research model shown in Figure 1 was established in this paper. 


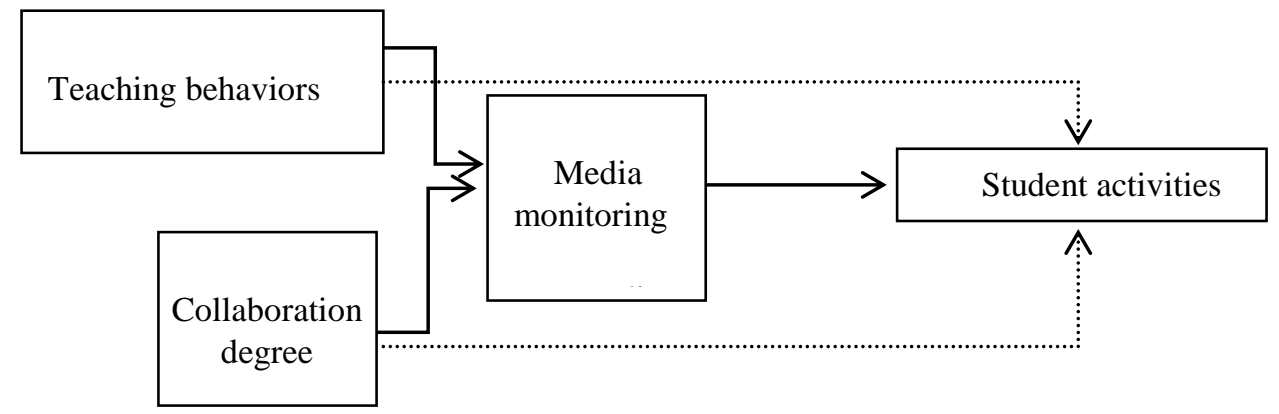

Fig. 1. Analytical model of this research

\section{$3 \quad$ Research design}

\subsection{Variable measurement}

In this paper, the data were collected through questionnaire survey. In the model, the measurement items of all independent and dependent variables derived from the related revised mature scales. All latent variables were measured using the 5-point Likert scale, where 1 meant "disagree very much" and 5 represented "agree very much". Before the formal survey, a total of 58 undergraduates (sophomores to seniors) were pre-surveyed to ensure that the reliability and validity of scale fulfilled the requirements. The scale was moderately adjusted until it is in accordance with the Chinese context. In the end, the questionnaire used to collect data included two parts: measurement scale of four latent variables, specifically involving four items of teaching behavior, three items of collaboration degree, four items of media monitoring, and three items of student activities.

\subsection{Data collection}

The data information used in this paper is derived from a provincial-level research project of the author. In this paper, a finance and economics-type general institute of higher education that comprehensively conducted online teaching after the beginning of the spring semester in 2020 was selected in this paper. The formal data collection was implemented in the form of "offline paper questionnaire + online questionnaire", and the invitation for filling the questionnaires was released via QQ group, a WeChat group, MOOC platform and network learning community. Through the careful screening of each submitted questionnaire, the questionnaires of respondents without online learning experience and the disqualified questions were excluded. The questionnaires were distributed to sophomore, junior, and senior students in this university. The questionnaire survey contents included two parts: basic information of users and questionnaire response. A total of 875 questionnaires were distributed, 573 ones 
were collected, among which 573 ones were valid, so the effective rate was $63.18 \%$. The basic information of respondents is listed in Table 1. It could be seen from Table 1 that the samples were of favorable representation.

Table 1. Basic information of respondents

\begin{tabular}{|c|c|c|c|}
\hline Classification & Type & Quantity & Proportion \\
\hline \multirow{2}{*}{ Gender } & Male & 149 & $41.16 \%$ \\
\cline { 2 - 4 } & Female & 213 & $58.84 \%$ \\
\hline \multirow{3}{*}{ Grade } & Sophomore & 114 & $31.49 \%$ \\
\cline { 2 - 4 } & Junior & 137 & $37.85 \%$ \\
\cline { 2 - 4 } & Senior & 111 & $30.66 \%$ \\
\hline
\end{tabular}

\section{Data analysis and results}

\subsection{Measurement model}

The model was verified in this paper through the two-step method. To ensure the effectiveness of measurement, the sufficiency (reliability and validity were included) of measurement model was measured using the latent variables in "confirmative factor analysis" model before the structural model was analyzed. In this paper, the Cronbach's $\alpha$ coefficient and composite reliability were used to evaluate the internal consistency of measurement model, where the former was a conservative estimate of measurement reliability and the latter would always overestimate the internal consistency reliability of the measurement, which resulted in a relatively high reliability estimate. The reliability analysis was conducted in this paper via SPSS22.0 for 11 observable variables of 4 latent variables: teaching mood, collaboration degree, media monitoring and student activities. As seen in Table 1, the overall Cronbach's $\alpha$ coefficient value of questionnaire was 0.920 , while those of four latent variables (teaching behaviors, collaboration degree, media monitoring and student activities) were 0.798 , $0.910,0.831$, and 0.767 , respectively, indicating good consistency of measurement indexes and strong questionnaire homogeneity. The Cronbach's $\alpha$ coefficients of all latent variables and their composite reliability were all greater than the threshold (0.70) and did not exceed 0.95, manifesting the good internal consistency of the measurement of latent variables.

In this paper, the convergence validity and discriminatory validity of scale were verified using the "confirmative factor analysis", where the former reflected the correlation between the items of the same latent variable and the latter reflected the difference between different latent variables. The evaluation of convergence validity was tested through average variance extracted (AVE) and factor loading significance. It could be seen from Table 2 that the AVE values of all latent variables were greater than 0.50 , while the standard factor loading coefficients of all observable variables were greater than 0.5 , manifesting the excellent construct validity of each latent variable. The factor loading and cross-loading analysis also showed that the load of 
measurement items on their theoretical latent variables was significantly higher than the cross-load on the other latent variables. Moreover, the square root of AVE of each latent variable was greater than the correlation coefficient between this latent variable and any other latent variable, indicating that the measurement of latent variables in this paper has enough discriminatory validity.

Table 2. Sample validity, reliability and factor analysis results

\begin{tabular}{|c|c|c|c|c|c|}
\hline Latent variable & Observable variable & $\begin{array}{c}\text { Standard } \\
\text { factor load }\end{array}$ & AVE & \multicolumn{2}{|c|}{ Cronbach's $\alpha$} \\
\hline \multirow{4}{*}{ Teaching behavior a } & Language behavior a1 & 0.508 & \multirow{4}{*}{0.624} & \multirow{4}{*}{0.798} & \multirow{14}{*}{0.920} \\
\hline & Questioning behavior a2 & 0.666 & & & \\
\hline & Posture behavior a3 & 0.675 & & & \\
\hline & Blackboard-writing behavior a4 & 0.648 & & & \\
\hline \multirow{3}{*}{$\begin{array}{l}\text { Collaboration degree } \\
\mathrm{b}\end{array}$} & Independent teaching b1 & 0.797 & \multirow{3}{*}{0.847} & \multirow{3}{*}{0.910} & \\
\hline & Interactive teaching b2 & 0.865 & & & \\
\hline & Aided teaching b3 & 0.879 & & & \\
\hline \multirow{4}{*}{ Media monitoring c } & Media operation c1 & 0.650 & \multirow{4}{*}{0.665} & \multirow{4}{*}{0.831} & \\
\hline & Monitoring \& management c2 & 0.706 & & & \\
\hline & Result feedback c3 & 0.661 & & & \\
\hline & Language frequency c4 & 0.641 & & & \\
\hline \multirow{3}{*}{$\begin{array}{l}\text { Student } \\
\text { activity d }\end{array}$} & Learning progress $\mathrm{d} 1$ & 0.501 & \multirow{3}{*}{0.686} & \multirow{3}{*}{0.767} & \\
\hline & Task completion $\mathrm{d} 2$ & 0.762 & & & \\
\hline & Teaching evaluation $\mathrm{d} 3$ & 0.791 & & & \\
\hline
\end{tabular}

In this paper, the KMO sample measurement and Bartlett's sphericity test were implemented for the survey data via SPSS22.0 software. The results showed that the KMO value was 0.916 , which was greater than the critical value, 0.7. Meanwhile, the $\mathrm{X}$ value of Bartlett's test was 2,912.051 and $\mathrm{P}<0.001$. Therefore, the survey data were of high correlation, being suitable for the factor analysis.

Table 3. KMO and Bartlett's Sphericity Test results

\begin{tabular}{|c|c|c|}
\hline \multicolumn{2}{|l|}{ KMO } & 0.916 \\
\hline \multirow{3}{*}{ Bartlett's Sphericity Test } & Approximate Chi-square & 2912.051 \\
\hline & df & 91 \\
\hline & Sig & 0.000 \\
\hline
\end{tabular}

\subsection{Overall model fitting and hypothesis testing}

The goodness of fit between the model and data was evaluated by selecting seven indexes: Chi-square degree of freedom, GFI, RMSEA, RMR, CFI, NFI, and NNFI. It should be noted from Table 4 that the measured values of five fitted indexes all fulfilled the requirements of the suggested values, indicating the overall high goodness of fit between measurement equation model and data. 
Table 4. Model fitting indexes

\begin{tabular}{|l|c|c|c|c|c|c|c|}
\hline Common index & $\boldsymbol{\chi}^{2} / \mathbf{d f}$ & GFI & RMSEA & RMR & CFI & NFI & NNFI \\
\hline Judgment criterion & $<3$ & $>0.9$ & $<0.10$ & $<0.05$ & $>0.9$ & $>0.9$ & $>0.9$ \\
\hline Value & 3.035 & 0.918 & 0.075 & 0.06 & 0.95 & 0.927 & 0.936 \\
\hline
\end{tabular}

The path coefficient of structural equation model (SEM) was calculated using Stata16.0, and the relationships between latent variables and those between latent variables and observable variables were revealed, as seen in Table 5.

Table 5. Model regression coefficient

\begin{tabular}{|l|c|c|c|c|c|c|c|}
\hline $\mathbf{X}$ & $\rightarrow$ & $\mathbf{Y}$ & Nonstandard regression coefficient & $\mathbf{S E}$ & $\begin{array}{c}\mathbf{Z} \\
\text { (CRvalue) }\end{array}$ & $\mathbf{p}$ & $\begin{array}{c}\text { Standard regression } \\
\text { coefficient }\end{array}$ \\
\hline $\mathrm{A}$ & $\rightarrow$ & C & 0.722 & 0.098 & 7.346 & 0.000 & 0.730 \\
\hline $\mathrm{A}$ & $\rightarrow$ & D & -0.169 & 0.089 & -1.893 & 0.058 & -0.201 \\
\hline $\mathrm{B}$ & $\rightarrow$ & C & 0.054 & 0.045 & 1.211 & 0.226 & 0.086 \\
\hline $\mathrm{B}$ & $\rightarrow$ & D & 0.098 & 0.033 & 2.942 & 0.003 & 0.182 \\
\hline $\mathrm{C}$ & $\rightarrow$ & D & 0.819 & 0.114 & 7.153 & 0.000 & 0.966 \\
\hline
\end{tabular}

As shown in Figure 2, the proposed hypotheses H1, H2 and $\mathrm{H} 3$ all held true.

1. It is verified that teaching behaviors have negative effects on student activities, which is largely consistent with most previous conclusions. The teachers' language behaviors show a negatively strong effect on student activities, namely, teachers lecture excessively, occupy a large amount of classroom teaching time and control the initiative of teaching activities, while students cannot do anything but passively listen, thus they can hardly generate active learning activities. In the teaching process under the information-based teaching environment, teacher lecturing still plays a dominant role. Aside from the traditional lectures, if teachers excessively take advantage of PPT in cooperation with lecturing and blackboard-writing behaviors, this will greatly compress the student activity time in classroom, thus reducing the occurrence of student activities. The proportion of indirect to direct influences of teaching language presents a weak and positive correlation with student activities. In classroom teaching, the more the teachers tend to provide indirect language effects on student feedback and questioning, the more they can facilitate student activities. Although teacher questioning exerts an obscure promoting effect on students' learning activities, it can also play a regulatory role in student activities.

2. The collaboration degree is verified to exert a positive effect on student activities, and the teacher feedbacks on students may also have a positive influence on student activities. The higher the ratio of feedbacks given by teachers to student $\mathrm{Q} \&$ A, the more they can motivate the student activities. In the analyzed class example, the correlation between teachers' feedback behavior and student activities does not reach the significance level, mainly because teacher behaviors, such as giving feedbacks to student Q \& A and providing students with guiding opinions, rarely appear in classroom. 
3. The positive effect of media monitoring on student activities is verified. Teachers present and transmit the teaching information and essentials in information-based classroom teaching using the traditional and modern digital media. These behaviors occupy a certain time, thus naturally reducing the opportunity of student activities. It can be known by combining the concrete teaching process that the media technology has been used by teachers. No matter in simple multimedia classroom, whether it is an interactive electronic whiteboard environment or one-to-one digital classroom or wisdom classroom, multimedia equipment is mainly used to prevent the teaching contents, but it is failing to exert the technical advantages and interaction effect; meanwhile, teachers are the main manipulators of technology media in the teaching process, where students cannot use the media according to their own learning needs. The implementation of information-based classroom management has considerably helped teachers to rid of conflict between imparting the contents and teaching the students, eliminating their helplessness in the face of bag learning atmosphere. The fair and just teaching management should be realized by virtue of systematic, normalized, and standardized characteristics of information management, and the teachers and students should be united to reach the common goalstudent growth and development—under their joint recognition and cooperation.

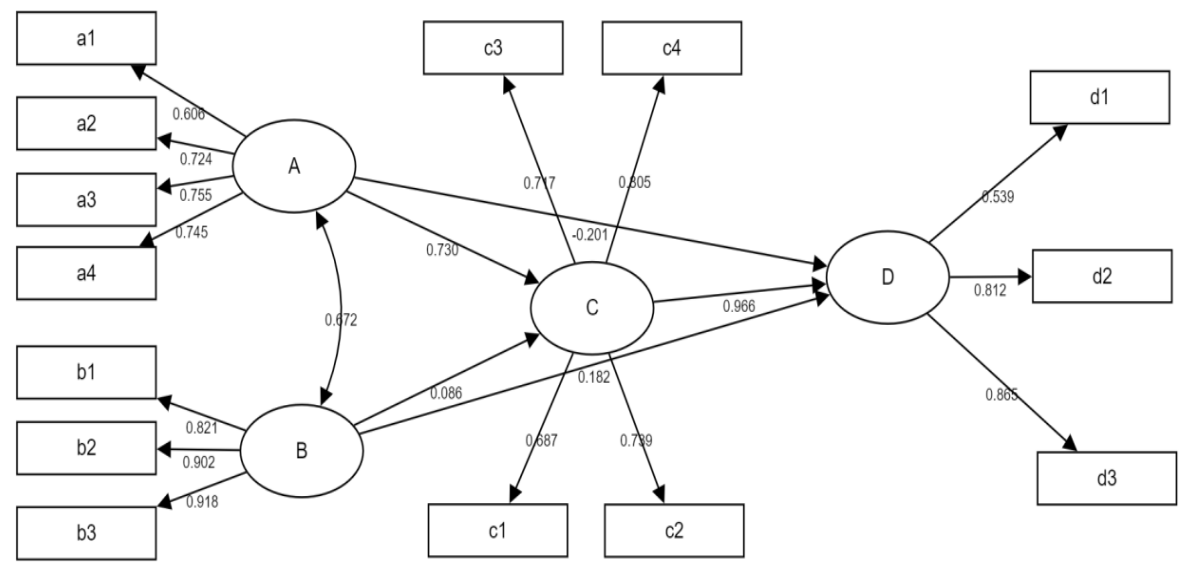

Fig. 2. SEM result map

\section{Conclusion}

Results revealed that teaching behaviors, collaboration degrees, and media monitoring have excessively strong positive correlations with student activities, indicating that regardless of what teaching environment and what information technologies and media are used by teachers in the teaching process, student learning behaviors and activities can be changed when teachers adjust and change their teaching behaviors. This explains why the utilization of information technologies and media resources in the current educational circles does not bring about the teaching reform or changes in 
student learning. Teachers and education administrators should be aware that if teaching behaviors are not changed, student learning behaviors will also not be changed, thus teachers should try to change and adjust their teaching behaviors when using the technology media. The teaching reform under the support of information technology can harvest substantial performance only when teachers possess the informationbased teaching concept, knowledge, and skills and exert efforts to change their teaching behaviors.

\section{Acknowledgment}

This work was supported by the training program for young key teachers of Henan Higher Vocational Schools (2019 GZGG018), the training program for Young Key teachers of Henan Polytechnic Institute (201901), and the research and practice program for teaching reform of higher education in Henan Province(2017 SJGLX144, 2019 SJGLX697).

\section{$7 \quad$ References}

[1] Teo, T., Lee, C. B., Chai, C. S., \& Su, L. W.. Assessing the intention to usetechnology among pre-service teachers in singapore and malaysia: a multigroup invariance analysis of the technology acceptance model (tam). Computers \& Education, 2009, vol.53 (3), pp. 1000-1009. https://doi.org/10.1016/j.compedu.2009.05.017

[2] Stes, A., Coertjens, L., \& Van Petegem, P.. Instructional development in higher education: Impact on teachers' teaching behaviour as perceived by students. Instructional Science, 2013,vol.41(6),pp.1103-1126. https://doi.org/10.1007/s11251-013-9267-4

[3] Wang, J., \& Jou, M.. Qualitative investigation on the views of inquiry teaching based upon the cloud learning environment of high school physics teachers from beijing, taipei, and chicago. Computers in Human Behavior, 2016, vol. 60, pp. 212-222. https://doi.org/10. 1016/j.chb.2016.02.003

[4] Babad, E., Sahar-Inbar, L., Hammer, R., Turgeman-Lupo, K., \& Nessis, S.. Student evaluations fast and slow: it's time to integrate teachers' nonverbal behavior in evaluations of teaching effectiveness. Journal of Nonverbal Behavior, 2021, pp. 1-18. https://doi.org/10. 1007/s10919-021-00364-4

[5] Fisher, D., Waldrip, B., \& den Brok, P.. Students' perceptions of primary teachers' interpersonal behavior and of cultural dimensions in the classroom environment. International Journal of Educational Research, 2005, vol. 43(1-2), pp. 25-38. https://doi.org/10.1016/j. ijer.2006.03.004

[6] Rankin, J., \& Brown, V.. Creative teaching method as a learning strategy for student midwives: A qualitative study. Nurse education today, 2016, vol. 38, pp. 93-100. https://doi.org/10.1016/j.nedt.2015.12.009

[7] Kindeberg, T..The significance of emulation in the oral interaction between teacher and students. Journal of Philosophy of Education, 2013, vol. 47(1), pp. 99-111. https://doi.org/ 10.1111/j.1467-9752.2012.00886.x

[8] Silverman, R. D., Proctor, C. P., Harring, J. R., Doyle, B., Mitchell, M. A., \& Meyer, A. G.. Teachers' instruction and students' vocabulary and comprehension: An exploratory 
study with English monolingual and Spanish - English bilingual students in Grades 3-5. Reading Research Quarterly, 2014, vol. 49(1),pp. 31-60. https://doi.org/10.1002/rrq.63

[9] Minamishima, E., \& Takahashi, T.. The influence of the usage of teaching materials and teachers' teaching behavior toward students' achievement. Frontiers in Psychology, 2017,vol.8(2) ,pp. 895. https://DOI:10.7219/jjses.27.21

[10] Schipper, T., Goei, S. L., Vries, S. D., \& Veen, K. V.. Developing teachers' self-efficacy and adaptive teaching behaviour through lesson study. International Journal of Educational Research, 2017,vol. 88 ,pp. 109-120. https://doi.org/10.1016/j.ijer.2018.01.011

[11] Menninga, A., van Geert, P., van Vondel, S., Steenbeek, H., \& van Dijk, M.. TeacherStudent Interaction Patterns Change During an Early Science Teaching Intervention. Research in Science Education, 2021, pp. 1-27. https://doi.org/10.1007/s11165-021-09997-3

[12] Liu, M. T., \& Yu, P. T.. Aberrant learning achievement detection based on person-fit statistics in personalized e-learning systems. Journal of Educational Technology \& Society, 2011,vol. 14(1),pp. 107-120.

[13] Hanson, J. M. , Paulsen, M. B., \& Pascarella, E. T.. Understanding graduate school aspirations: the effect of good teaching practices. Higher Education, 2016,vol. 71(5) ,pp. 735752. https://doi.org/10.1007/s10734-015-9934-2

[14] Li, R..Effect of synchronous web-based teaching combined with visually creative teaching under the background of information science.The Electronic Library, 2018,vol. 37(5),pp. 830-841. https://doi.org/10.1108/EL-02-2019-0023

\section{Author}

Linsheng Wang received a master degree in computer technology engineering at Huazhong University of Science and Technology in 2009. Since 2017, he has been an associate professor in the College of Electronic and information engineering of Henan Polytechnic Institute. His main research direction is the electronic information technology teaching.

Article submitted 2021-11-14. Resubmitted 2021-12-15. Final acceptance 2021-12-17. Final version published as submitted by the author. 